


\title{
Investigating the effect of silica aerogel content on the mechanical properties of epoxy resin system
}

\author{
Hasan Yavuz Ünal, Selay Sert Çok, Fatoş Koç, Nilay Gizli, Yeliz \\ Pekbey
}

Online Publication Date: 25 May 2019

URL: http://www.jresm.org/archive/resm2019.111me0201.html

DOI: http://dx.doi.org/10.17515/resm2019.111me0201

Journal Abbreviation: Res. Eng. Struct. Mater.

\section{To cite this article}

Unal HY, Çok SS, Koç F, Gizli N, Pekbey Y. Investigating the effect of silica aerogel content on the mechanical properties of epoxy resin system. Res. Eng. Struct. Mater., 2020; 6(1): 85-95.

\section{Disclaimer}

All the opinions and statements expressed in the papers are on the responsibility of author(s) and are not to be regarded as those of the journal of Research on Engineering Structures and Materials (RESM) organization or related parties. The publishers make no warranty, explicit or implied, or make any representation with respect to the contents of any article will be complete or accurate or up to date. The accuracy of any instructions, equations, or other information should be independently verified. The publisher and related parties shall not be liable for any loss, actions, claims, proceedings, demand or costs or damages whatsoever or howsoever caused arising directly or indirectly in connection with use of the information given in the journal or related means.

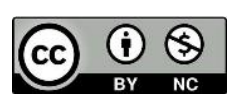

Published articles are freely available to users under the terms of Creative Commons Attribution - NonCommercial 4.0 International Public License, as currently displayed at here (the "CC BY - NC"). 


\title{
Research on Engineering Structures \& Materials \\ journal homepage: http://jresm.org
}

Research Article

\section{Investigating the effect of silica aerogel content on the mechanical properties of epoxy resin system}

\author{
Hasan Yavuz Ünal1,a, Selay Sert Çok²,b, Fatoş Koç2,c, Nilay Gizli2,d, Yeliz Pekbey¹,e \\ ${ }^{1}$ Department of Mechanical Engineering, Ege University, Izmir, Turkey \\ ${ }^{2}$ Department of Chemical Engineering, Ege University, Izmir, Turkey
}

\begin{abstract}
Article Info Abstract
Article history:

Received 01 Feb 2019

Revised 17 May 2019

Accepted 24 May 2019

Keywords:

Epoxy resin;

Silica aerogel;

Tensile strength;

Three-point bending

Nowadays, silica aerogels have been widely used in many applications due to their extremely low density, low thermal conductivity and high specific surface area. Many researchers have proved that the addition of the nanoparticles into thermoset polymers resin has influenced the mechanical properties of the composites. Epoxy resins are one of the mostly used thermoset polymers. Although they have superior mechanical strength, they are usually suffered from their fragile structure. There are several additives such as carbon nanotubes, nanoclay, calcite etc. that can be added to epoxy resins to enhance their mechanical properties such as tensile strength, modulus of elasticity, break strain. In this study, the silica aerogels were added as nano-fillers into epoxy to investigate the effect of the silica aerogel content on the mechanical performance of silica aerogel-epoxy composites. Two different silica aerogel-epoxy composites were produced with various silica aerogel content ( 0.5 and $1 \mathrm{wt}$. \%) and effect of aerogel amount on the mechanical and structural properties of final nanocomposites was investigated. Silica aerogels used in the study were synthesized by traditional sol gel method to obtain versatile silica aerogel-epoxy composites. Apart from the classically synthesized silica aerogels, aerogels in the present study contain short chained ionic liquid (IL) as porogenic agents. The effect of the addition of the silica aerogel on the tensile and flexural properties of final composites were observed by the measurement of the tension and threepoint bending tests, respectively according to ASTM standard. The results have shown that the mechanical behavior of the epoxy resin was significantly influenced by the silica aerogel addition. The mechanical strength of epoxy composite with silica aerogel addition was improved compared to that of the neat epoxy.
\end{abstract}

\section{Introduction}

Silica aerogels are extraordinary porous materials with numerous superior properties such as very low density $\left(0.003-0.5 \mathrm{~g} / \mathrm{cm}^{3}\right)$, high surface area $\left(500-1200 \mathrm{~m}^{2} / \mathrm{g}\right)$, and high porosity (80\%-99.8\%) [1-4]. Due to their outstanding properties aerogels are frequently used in many applications as thermal insulators [5], catalysis, chemical sensors [6], in drug delivery systems [7], acoustic insulators [8] and in space applications [9]. Due to their highly developed 3D porous structure, aerogels are also used as nano-fillers in several composites production, recently. Many researchers have showed that the addition of

\footnotetext{
*Corresponding author: yeliz.pekbey@ege.edu.tr

${ }^{a}$ orcid.org/0000-0003-1934-7445; b orcid.org/0000-0001-7595-2151; c orcid.org/0000-0002-2996-110X;

d orcid.org/0000-0002-7591-1365; ${ }^{\mathrm{e}}$ orcid.org/0000-0002-1024-8806

DOI: http://dx.doi.org/10.17515/resm2019.111me0201
}

Res. Eng. Struct. Mat. Vol. 6 Iss. 1 (2020) 85-95 
nanoparticles such as silica aerogels to polymers can improve mechanical, thermal, and electrical properties of epoxy in comparison with the neat composites [10,11]. Li et.al [2] have investigated the mechanical performance and the thermal conductivity of aramid fibers reinforced with silica aerogels. They concluded that inorganic fibers reinforced with silica aerogels can improve the compressive strength and flexural strength. There are also large amount of studies considering the improvement of mechanical, thermal, and electrical properties of epoxy resins $[12,13]$.

In the recent studies, silica aerogels have become a promising candidate as nano-fillers in many composite productions. Maghsoudi and Motahari, in their study, have focused on the mechanical, thermal, and hydrophobic properties of silica aerogel-epoxy composites. They measured the thermal conductivity and thermal stability of the nanocomposites with different silica aerogel contents. They have deduced that mechanical, thermal, and hydrophobic properties of silica aerogel-epoxy composites were enhanced by increasing the nanoparticle content [14]. Lei et al. have studied the thermal insulation performance and mechanical properties of silica aerogel monoliths by mixing graphene oxide. They measured the compressive modulus and the thermal conductivity of pure aerogel and composite aerogels. The results have showed that the thermal insulation property and compressive strength of silica aerogels were enhanced with the addition of graphene oxide in the silica matrix [15]. In another study, Li et al. investigated mechanical, thermal and flammability properties of glass fiber film/silica aerogel composites. These researchers showed that the elasticity and flexibility of the composites were found to be better than those of the silica aerogel, and could withstand large amounts of compressive strain without failure or cracking [16]. Zhou et al. have investigated mechanical performance and thermal stability of glass fiber reinforced silica aerogel composites based on co-precursor method by freeze-drying. They concluded that the silica aerogel composites showed remarkable mechanical strength and flexibility, which could endure large compressive and flexural strain without structural destroyed [17]. Salimian et al., in another study, proved that addition of small amount of silica aerogels into epoxy resin significantly increased the tensile strength, modulus of elasticity, toughness and glass transition temperature [18]. Due to sufficient pore size of silica aerogels, epoxy resin and silica aerogels are easily consociated. Besides that, mesopores in silica aerogels filled with epoxy according to dead pore ratio. Shafi et al. have used silica gel as a binder or filler in silica aerogel-glass fiber composites. Silica gels filled the gap or channel between glass fiber and silica aerogel. In this manner, thermal conductivity has decreased without make concessions in compression strength. They also conclude that higher than $5 \%$ silica gel addition increase the thermal conductivity [19]. Zhao et al. have investigated effects of precursor and catalyst contents on microstructural, mechanical, hydrophobicity and thermal conductivity [20]. EtOH/MTES (E) and $\mathrm{NH}_{4} \mathrm{OH} / \mathrm{MTES}(\mathrm{N})$ contained aerogels with different ratios of were synthesized by sol gel method. Young modulus and contact angle increased with lower (E). Additionally, linear shrinkage decreased with higher $(\mathrm{N})$ ratio. Thermal stability of aerogel was measured around $350^{\circ} \mathrm{C}$ and maximum contact angle was obtained as $145.6 \stackrel{\circ}{\circ}$. The lowest density and thermal conductivity belong to aerogels with $\mathrm{E}=10$ and $\mathrm{N}=3.6$. Aerogels could be used up to $40 \%$ strain without permanent deformation. There is hardly any study that investigates the silica aerogels containing different porogenic agents and functional group as a novel nano-fillers in epoxy resin systems. Hence, this study aims to include the ionic liquids in sol-gel process to enhance the morphological and chemical characteristics of typical aerogels and therefore to yield a well-defined, mechanically reinforced aerogelepoxy nanocomposites.

In this study, the silica aerogel was added as nano-filler into epoxy to investigate effect of the silica aerogel on the mechanical performance of silica aerogel-epoxy composites. Silica 
aerogels in the study was prepared by sol-gel method, which is simply based on consequent hydrolysis and condensation reactions of a silica precursor in the presence of proper solvent and catalysts. Preparation of the sol, aging of the gel and drying stages are the crucial steps in the sol-gel method. Aging and drying periods are the key steps in the formation of three dimensional of porous network and should be carefully carried out. In the study, in addition to the classical sol components, organic salts with an extremely low vapor pressure called ionic liquids were also included in sol-gel steps to control the aging and drying steps and hence to obtained well-developed porous network.

Silica aerogels mediated with an imdazolium based ionic liquid were used in different amounts ( 0.5 and $1 \mathrm{wt}$. \%) in the production of silica aerogel-epoxy nanocomposites to investigate their mechanical properties in this study. The effect of the silica aerogel on the tensile and flexural properties of the final composites were observed by the measurement of the tension and three-point bending tests, respectively. The results have shown that the mechanical behavior of the epoxy resin was significantly influenced by the silica aerogel addition. The mechanical strength of epoxy composite with silica aerogel addition was improved compared to that of neat epoxy composites.

\section{Experimental}

\subsection{Preparation of the Silica Aerogels}

Tetraethylorthosilicate (TEOS) as silica precursor and 3-aminopropyltriethoxy-silane (APTES) as co-precursor were acquired from Sigma Aldrich. 1-Ethyl-3-methylimidazolium bis(trifluoromethanesulfonyl)imide $\left(\mathrm{EMIMTF}_{2} \mathrm{~N}\right)$ was utilized as the short-chain imidazolium based ionic liquid, and 3-methacryloxypropyltrimethoxysilane (MEMO) as surface modification agent were purchased from Sigma Aldrich. Ethanol (EtOH) and nhexane were used as solvents and hydrochloric acid ( $\mathrm{HCl}$ ) was used as the acid catalyst.

The silica aerogels were prepared by following one-step sol-gel processes containing ionic liquid. During the synthesis, TEOS was firstly hydrolyzed by using $0.01 \mathrm{M} \mathrm{HCl}$ for $90 \mathrm{~min}$ by stirring at $25^{\circ} \mathrm{C}$. Then APTES was added to the sol to start condensation reaction. The sol component consists of TEOS: APTES: IL: EtOH: $\mathrm{HCl}$ with the molar ratios of

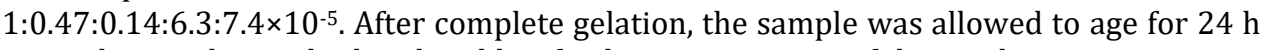
in a polypropylene cylindrical mold to further continuation of the condensation reaction. Subsequently, the solvent exchange was carried out by treating the wet gels with fresh nhexane for $12 \mathrm{~h}$ to ensure complete removal of the impurities within the gel. Then, surface modification was conducted by immersing the sample in silylating agent (MEMO) diluted with n-hexane at a volumetric percent of $50 \%$ at room temperature. Finally, silica aerogel samples containing ionic liquid were dried in ambient condition.

\subsection{Composite Preparation}

The epoxy resin, hardener and mold release were purchased from Fibermak Co. (Turkey). As epoxy resin, diglycidyl ether of bisphenol A (DGEBA, trade name F1664) and as amine hardener, F3486 were used. The viscosity, density, color and glass transition temperatures were $1250-1450 \mathrm{mPa} \mathrm{s}, 1,1-1,2 \mathrm{~g} / \mathrm{cm}^{3}$, colorless and $80^{\circ} \mathrm{C}$, respectively. A calculated amount of silica aerogel (0.5-1 wt. \%) was distributed into epoxy resin using ultrasonic homogenizers (Hielscher, UP400S, $400 \mathrm{~W}$ and $24 \mathrm{kHz}$ ) (Figure 1). Half an hour of sonication was applied to silica aerogel-epoxy solution. The working conditions of Sonicator were 1 cycle and 100\% amplitude. During sonication, solution temperature increases, for that reason, the mixture was taken into an ice bath. 


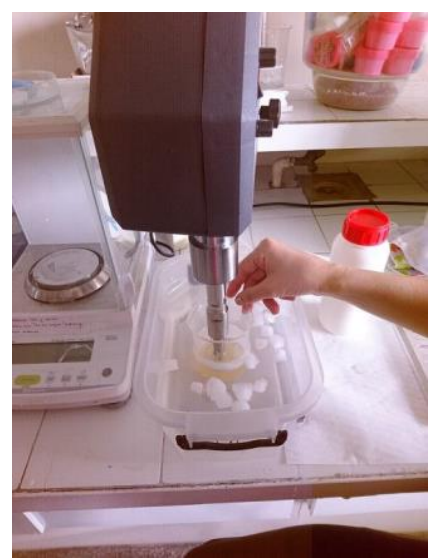

Fig. 1 Ultrasonic homogenizer for dispersion silica aerogel.

Mold release was applied to all surfaces of aluminum mold for three times to easily remove the completely cured samples from the mold. Entrapped air was removed from both silica aerogel-epoxy and silica aerogel-epoxy-hardener mixture by using vacuum pump. When no bubbles remained in mixture, liquid was slowly poured into the mold (Figure 2).

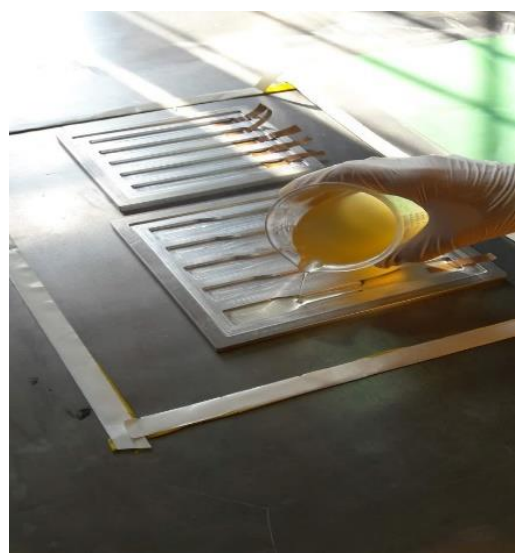

Fig. 2 Pouring mixture into aluminum mold.

Curing of the prepared samples was carried out by arranging the sequence of process. Molds were initially kept at $50{ }^{\circ} \mathrm{C}$ for $5 \mathrm{~h}$. Then the temperature slowly decreased down to ambient temperature. After that, the samples were removed from slots. Three sets of composites were shown in Figure 3. 


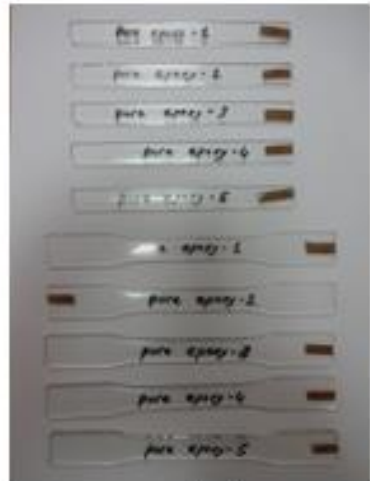

(a)

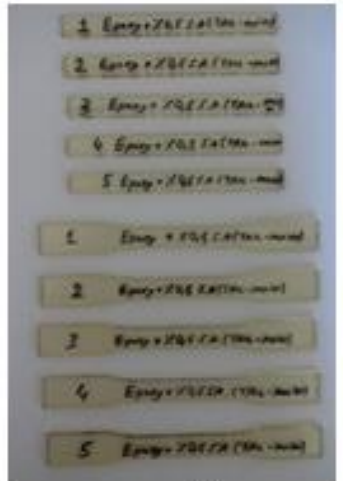

(b)

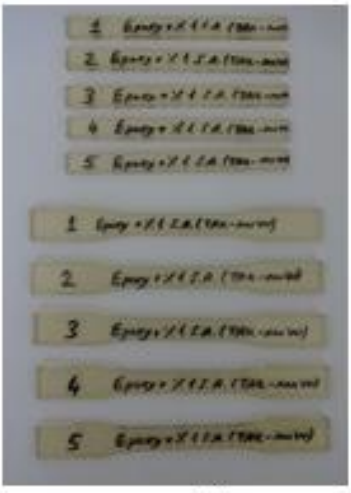

(c)

Fig. 3 Tensile and three point bending samples

(a) pure epoxy, (b) epoxy - 0.5 wt. \% silica aerogel, (c) epoxy - 1 wt. \% silica aerogel.

\subsection{Characterizations}

To identify the microstructure of the composites, Scanning Electron Microscopy (SEM) images of the samples were taken with various magnification rates.

Tensile tests were carried out with a universal testing machine (Shimadzu). These tests were performed according to ASTM D638-14 and the loading rate was set as $5 \mathrm{~mm} / \mathrm{min}$ at $25^{\circ} \mathrm{C}$ until material failure. The geometry of samples was dog bone therefore rupture was observed from the thinner section. During the test, load and displacement data were directly received. Then, the load displacement curve for each test was converted to a stress-strain curve. Stress and strain formulas were given in Eq. 1 and 2:

$$
\begin{aligned}
& \sigma=\frac{F}{A} \quad[\mathrm{MPa}] \\
& \varepsilon(\%)=\frac{\Delta L}{L} x 100
\end{aligned}
$$

where $F$ is force $(\mathrm{N}), A$ is area $\left(\mathrm{mm}^{2}\right), \Delta \mathrm{L}$ is elongation $(\mathrm{mm})$ and $\mathrm{L}$ is gauge length $(\mathrm{mm})$.

Three-point bending test was performed with a Shimadzu machine according to ASTM D790-17. In this test, the rectangular cross section samples were prepared with dimensions of $127 \times 12.7 \times 3.2 \mathrm{~mm}$ as shown in Figure 3. Loading rate was set at $2 \mathrm{~mm} / \mathrm{min}$. The ratio of support span to thickness was 16. Stress-strain formulas in three-point bending were given in Eq. 3 and 4:

$$
\begin{aligned}
& \sigma=\frac{3 F l}{2 w t^{2}} \quad[\mathrm{MPa}] \\
& \varepsilon(\%)=\frac{6 \delta t}{l^{2}} \times 100
\end{aligned}
$$

where $F$ is force $(N), w$ is width $(\mathrm{mm})$, $t$ is thickness $(\mathrm{mm})$ and $l$ is support span $(\mathrm{mm}), \delta$ is deflection (mm). 


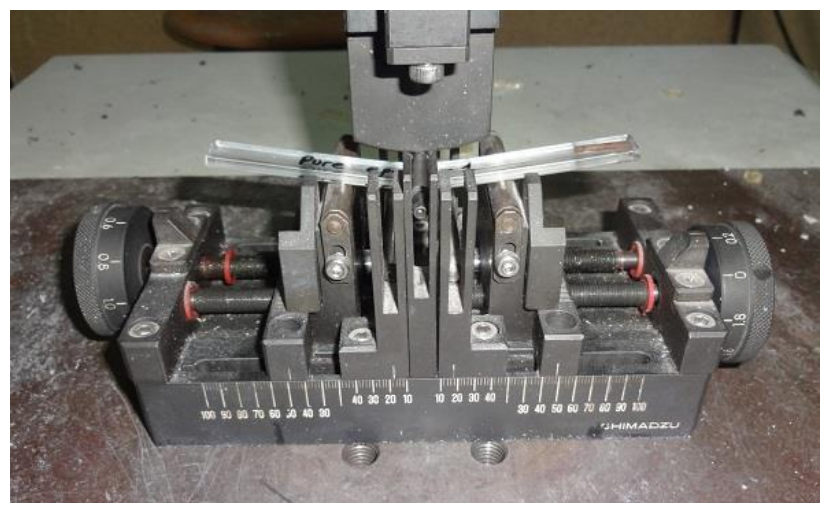

Fig. 4 Photograph of the three-point bending test.

Tensile and three-point bending tests were repeated five times to achieve reliable results for the neat epoxy and each of silica aerogel-epoxy composites.

\section{Results and Discussions}

\subsection{Morphology of the Composites}

SEM images of the nanocomposites were obtained to investigate the morphology of the final composites and to observe the distribution of the silica aerogel powders in epoxy resin. The SEM images of the ionic liquid mediated silica aerogel/epoxy nanocomposites were shown in Fig. 5. It can be seen from Fig. 5a-c that the morphology of nanocomposites became rougher in the presence of silica aerogels. The small amount of silica aerogel was uniformly dispersed in epoxy resin, which resulted in good interfacial adhesion between filler and matrix. However, as the amount of silica aerogel addition was increased up to 1 wt. \% in epoxy, aerogel particles tend to agglomerate as small clusters. The possible reason for this situation can be the interaction between functional groups on the filler surface and matrix that leads less homogeneous dispersion. On the other hand, silica aerogel-epoxy composite with $0.5 \%$ silica aerogel addition seemed to be distributed more homogenously than the composite having $1 \%$ silica aerogel addition.

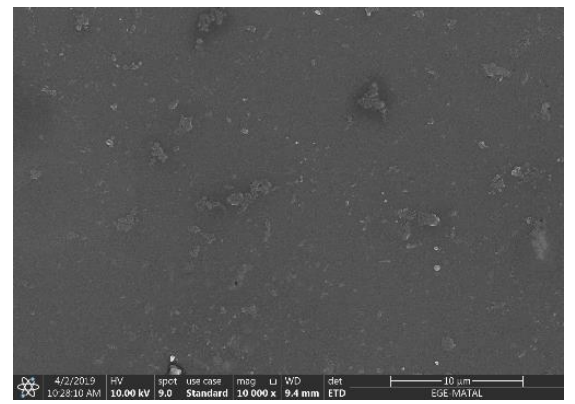

(a)

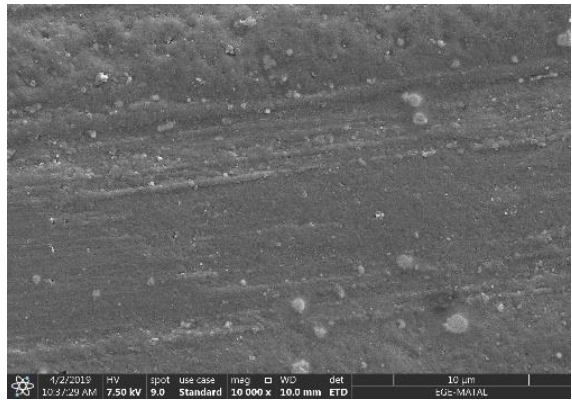

(b) 


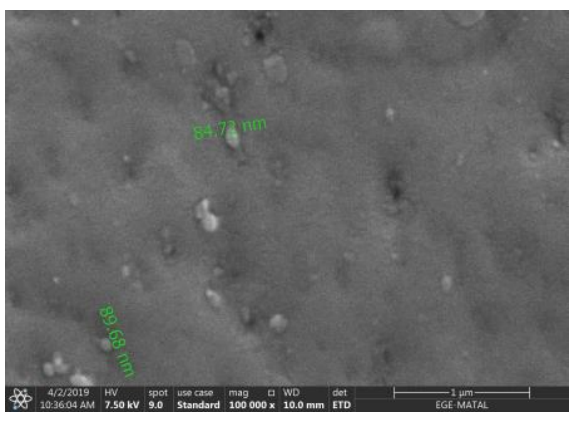

(c)

Fig 5. SEM images of SA-epoxy nanocomposites

$$
\text { a- Epoxy + } 0.5 \% \text { S.A, b- Epoxy + } 1 \text { \% S.A, c- Epoxy + } 0.5 \% \text { S.A. }
$$

\subsection{Tensile Properties of the Composites}

Tensile tests were performed to measure the effect of the silica aerogel particles on the mechanical properties of the epoxy composites. Tensile properties of the silica aerogelepoxy composites were reported in Table 1.

Table 1 Tensile properties of silica aerogel-epoxy composite.

\begin{tabular}{cccc}
\hline Specimen/Value & $\begin{array}{c}\text { Ultimate Stress } \\
\text { (MPa) }\end{array}$ & $\begin{array}{c}\text { Modulus of } \\
\text { Elasticity (MPa) }\end{array}$ & Break strain (\%) \\
\hline Pure Epoxy & $41.725 \pm 2.666$ & $316.028 \pm 17.797$ & $14.350 \pm 2.388$ \\
\hline Epoxy + 0.5 \% S.A & $49.207 \pm 2.611$ & $598.252 \pm 49.907$ & $10.951 \pm 1.529$ \\
\hline Epoxy + 1 \% S.A & $53.939 \pm 2.022$ & $566.204 \pm 7.993$ & $11.760 \pm 0.951$ \\
\hline
\end{tabular}

The modulus of elasticity (Young's modulus) of the samples was identified by the slope of the initial linear portion of the stress-strain curve obtained during tensile tests. Stress strain curve of the one of the specimens in each group was shown in Figure 6.

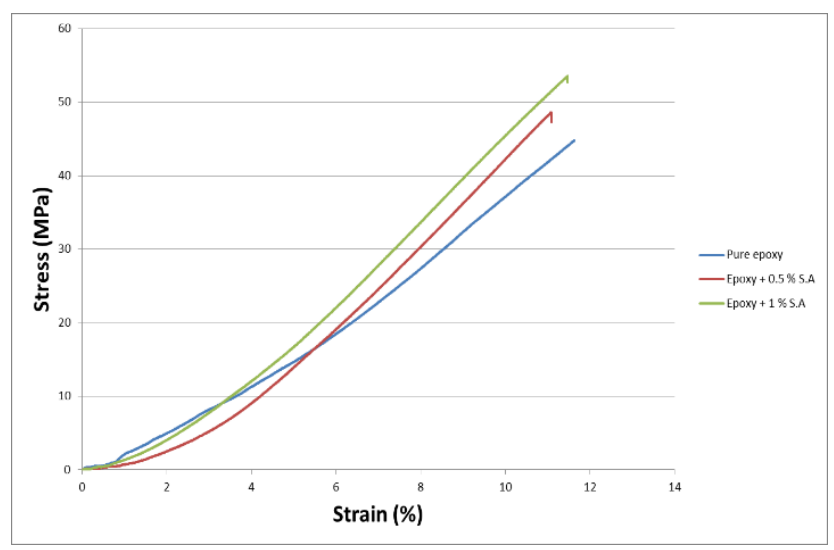

Fig. 6 Tensile stress - strain diagram of nanocomposites

The first considerable outcome was that the tensile strength significantly increased with addition of small amount of silica aerogel. The increment of tensile strength was $18 \%$ and 
$29 \%$ compared to pure epoxy for 0.5 and $1 \mathrm{wt}$. \% silica aerogel composites, respectively. In addition, rigidity of epoxy composite increased with silica aerogel addition. Approximately, twice of modulus of elasticity was obtained with $0.5 \mathrm{wt}$. \% silica aerogel addition. The reason for increment of tensile strength and modulus was due to the high specific surface area of silica aerogel. Because of this, content area between silica aerogel and epoxy was sufficient to transfer forces to matrix.

However, elongation at break for silica aerogel composites was smaller than that of pure epoxy. The decrement of break strain was found $24 \%$ and $18 \%$ for $0.5 \mathrm{wt}$. $\%$ and $1 \mathrm{wt}$. \% silica aerogel composites, respectively. Silica aerogel may have caused micro-crack formation and early failure.

\subsection{Flexural Properties of the Composites}

The reaction of composite for bending moment was obtained with three-point bending test. Samples were placed on two stationary supports and load was applied on the middle of the sample. Flexural stress, modulus and break strain were calculated. Flexural modulus was obtained with drawing a tangent line to stress-strain curve. Flexural properties of the silica aerogel-epoxy composites were reported in Table 2.

Table 2 Flexural properties of silica aerogel-epoxy composite.

\begin{tabular}{cccc}
\hline Specimen/Value & $\begin{array}{c}\text { Ultimate Bending Stress } \\
\text { (MPa) }\end{array}$ & $\begin{array}{c}\text { Bending Modulus } \\
\text { (MPa) }\end{array}$ & $\begin{array}{c}\text { Break strain } \\
\text { (\%) }\end{array}$ \\
\hline Pure Epoxy & $108.484 \pm 6.199$ & $2960.623 \pm 188.427$ & $13.113 \pm 3.189$ \\
\hline Epoxy + 0.5 \% S.A & $115.892 \pm 4.894$ & $3475.490 \pm 169.119$ & $13.610 \pm 0.211$ \\
\hline Epoxy + 1 \% S.A & $99.497 \pm 4.190$ & $2831.092 \pm 158.945$ & $13.434 \pm 1.292$ \\
\hline
\end{tabular}

Flexural properties divided from tensile properties. Ultimate bending stress and bending modulus were increased for $0.5 \mathrm{wt}$. \% and decreased for $1 \mathrm{wt}$. \% silica aerogel composites. Composite with 0.5 wt. \% showed $7 \%$ and $17 \%$ increase in bending stress and bending modulus, respectively. Additionally, increase in flexural break strain was not significant. Only $4 \%$ increment was observed. The stress - strain diagram for one specimen in each group was plotted in Fig 7.

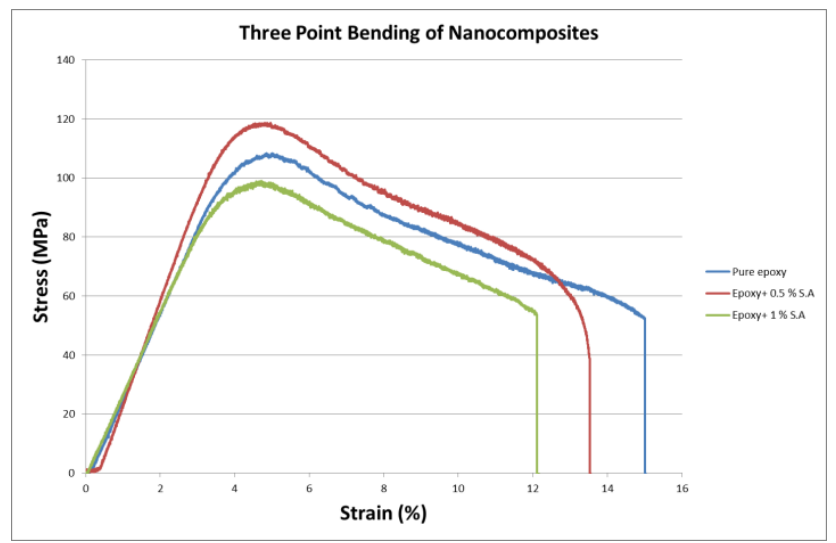

Fig. 7 Three point bending stress - strain diagram of nanocomposites 
When silica aerogel content was $1 \mathrm{wt}$. \%, ultimate bending stress and bending modulus were smaller than that of pure epoxy. $8 \%$ and $4 \%$ decrement were observed, respectively. Moreover, flexural break strain showed medium results. It was located between pure and containing $0.5 \mathrm{wt}$. \% silica aerogel composite. By adding $1 \mathrm{wt}$ \% silica aerogel into epoxy, flexibility of the composite was increased. Since $0.5 \%$ silica aerogel containing epoxy was produced homogenously, it was resulted in good bending properties. On the other hand, increasing aerogel content in epoxy resin has caused some agglomeration within the matrix and hence, it resulted with local concentrated stress and bending strength decreased for this reason.

\section{Conclusion}

In this study, the effect of silica aerogel on the mechanical properties of epoxy composites was investigated. Silica aerogels were produced with sol gel method. Two silica aerogelepoxy composites with different silica contents were prepared to perform mechanical tests. Silica aerogels were distributed into epoxy resin by ultrasonic cavitation technique. ASTM D638-14 and D790-17 standard mechanical tests were performed. The mechanical analysis displayed that the tensile and flexural properties was influenced by the addition of the silica aerogel with increasing weight percent from $0.5 \mathrm{wt}$. \% to $1 \mathrm{wt}$. \%. In addition, significant improvements in the Young's modulus (89\%), tensile strength (18\%) and flexural modulus (17\%) were observed with the optimal content of silica aerogel (0.5 wt. $\%)$. Due to the large pore volume of silica aerogels and strong interaction with epoxy, mechanical properties of nanocomposites were increased. Epoxy resin filled the pore of silica aerogel and structural rigidity increased.

The results showed that the break strain of the neat epoxy composite decreased with adding silica aerogel content in tensile test. Due to the strong interfacial interaction between silica aerogel and epoxy resin, nanocomposites showed rigid structure. Although strength increased, break strain value decreased due to brittle behavior of the nanocomposites. The maximum bending strength, modulus and strain at break was attributed to the composite containing $0.5 \mathrm{wt}$. \% silica aerogel in comparison to the neat epoxy. However, the flexural properties of the composites decreased when highest silica aerogel content was used. As seen from the SEM images, the bending properties of the 1 wt. \% silica aerogel containing nanocomposite, which tends to agglomerate, was lower than that of pure epoxy.

\section{Acknowledgements}

The Scientific and Technological Research Council of Turkey financially supported this research (TUBITAK, 116M 350). The authors deeply appreciate the supports from the Scientific and Technological Research Council of Turkey. The authors also very thankful to Müjde Garip for kind support during experimental studies.

\section{References}

[1]. Li M, Jiang H, Xu D, Hai O, and Zheng W. Low density and hydrophobic silica aerogels dried under ambient pressure using a new co-precursor method. Journal of Non$\begin{array}{lllll}\text { Crystalline } & \text { Solids. } & 2016 & \text { Nov; } & 452:\end{array}$ https://doi.org/10.1016/j.jnoncrysol.2016.09.001

[2]. Li Z, Cheng X, He S, Shi X, Gong L, and Zhang H. Aramid fibers reinforced silica aerogel composites with low thermal conductivity and improved mechanical performance. Compos. Part A Appl. Sci. Manuf.2016; 84: 316-325. https://doi.org/10.1016/j.compositesa.2016.02.014 
[3]. Laskowski J, Milow B, and Ratke L. Aerogel-aerogel composites for normal temperature range thermal insulations. Journal of Non-Crystalline Solids. 2016; 441: 42-48. https://doi.org/10.1016/j.jnoncrysol.2016.03.020

[4]. Soleimani Dorcheh A and Abbasi M. H. Silica aerogel; synthesis, properties and characterization. J. Mater. Process. Technol. 2008; 199-1:10-26. https://doi.org/10.1016/i.jmatprotec.2007.10.060

[5]. Parmenter K. E. Mechanical properties of silica aerogels. Journal of Non-Crystalline Solids. 1996 Nov; 1: 79-189.

[6]. Amonette J. E, and Matyáš J. Functionalized silica aerogels for gas-phase purification, sensing, and catalysis: A review. Microporous Mesoporous Materials. 2017; 250: 100 119. https://doi.org/10.1016/j.micromeso.2017.04.055

[7]. Maleki H, Dur L, and Garc C. A. Synthesis and Biomedical Applications of Aerogels: Possibilities and Chal- lenges Hajar. Advance Colloid Interface Science. 2016; 236: 1 27. https://doi.org/10.1016/j.cis.2016.05.011

[8]. Buratti C, Merli F, and Moretti E. Aerogel-based materials for building applications: Influence of granule size on thermal and acoustic performance. Energy Buildings. 2017; 152: 472-482. https://doi.org/10.1016/j.enbuild.2017.07.071

[9]. Berthon-Fabry S, Hildenbrand C, Ilbizian P, Jones E, and Tavera S. Evaluation of lightweight and flexible insulating aerogel blankets based on ResorcinolFormaldehyde-Silica for space applications. Eur. Polym. J. 2017 May; 93: 403-416. https://doi.org/10.1016/j.eurpolymj.2017.06.009

[10]. Li Z, Gong L, Cheng X, He S, Li C, Zhang H. Flexible silica aerogel composites strengthened with aramid fibers and their thermal behavior. Materials and Design. 2016; 99: 349-55. https://doi.org/10.1016/j.matdes.2016.03.063

[11]. Chal B, Foray G, Yrieix B, Masenelli-Varlot K, Roiban L, Chenal J-M. Durability of silica aerogels dedicated to superinsulation measured under hygrothermal conditions. Microporous and Mesoporous Materials. 2018; 272: 61-69. https://doi.org/10.1016/i.micromeso.2018.05.047

[12]. Maleki H, Durães L, Portugal A. An overview on silica aerogels synthesis and different mechanical reinforcing strategies. J Non Cryst Solids. 2014; 385: 55-74. https://doi.org/10.1016/j.jnoncrysol.2013.10.017

[13]. Salimian S, Zadhoush A, Talebi Z, Fischer B., Winiger P., Winnefeld F., Zhao S, Barbezat M, Koebel M M, Malfait W J, Silica Aerogel-Epoxy Nanocomposites: Understanding Epoxy Reinforcement in Terms of Aerogel Surface Chemistry and Epoxy-Silica Interface Compatibility, Applied Nano Materials, 2018; 1: 4179-4189. https://doi.org/10.1021/acsanm.8b00941

[14]. Maghsoudi K, Motahari S. Mechanical, thermal, and hydrophobic properties of silica aerogel-epoxy composites. J Appl Polym Sci. 2018;135(3):1-9. https://doi.org/10.1002/app.45706

[15]. Lei Y, Hu Z, Cao B, Chen X, Song H. Enhancements of thermal insulation and mechanical property of silica aerogel monoliths by mixing graphene oxide. Materials Chemistry $\quad$ and 183-190. https://doi.org/10.1016/j.matchemphys.2016.11.064

[16]. Li C, Cheng X, Li Z, Pan Y, Huang Y, Gong L. Mechanical, thermal and flammability properties of glass fiber film/silica aerogel composites. J Non Cryst Solids. 2017;457:52-59. https://doi.org/10.1016/j.jnoncrysol.2016.11.017

[17]. Zhou T, Cheng X, Pan Y, Li C, Gong L, Zhang H. Mechanical performance and thermal stability of glass fiber reinforced silica aerogel composites based on co-precursor method by freeze drying. Appl Surf Sci. 2018; 437: 321-328. https://doi.org/10.1016/i.apsusc.2017.12.146

[18]. Salimian S, Malfait W. J, Zadhoush A, Talebi Z, Naeimirad M. Fabrication and evaluation of silica aerogel-epoxy nanocomposites: Fracture and toughening 
mechanisms. Theoretical and Applied Fracture Mechanics. 2018; 97: 156-164. https://doi.org/10.1016/i.tafmec.2018.08.007

[19]. Shafi S, Navik R, Ding X, Zhao Y. Improved heat insulation and mechanical properties of silica aerogel/glass fiber composite by impregnating silica gel. Journal of NonCrystalline

Solids. 2019 503-504:

78-83. https://doi.org/10.1016/i.jnoncrysol.2018.09.029

[20]. Zhao Y, Li Y, Zhang R. Silica aerogels having high flexibility and hydrophobicity prepared by sol-gel method. Ceramics International. 2018; 44: 21262-21268. https://doi.org/10.1016/i.ceramint.2018.08.173 